Original Research Paper

\title{
A Systematic Review of Mobile-Based Assessment Acceptance Studies from 2009 to 2019
}

\author{
Ali Alrfooh', Muhammad Modi ${ }^{1}$ \\ ${ }^{1}$ Department of Computing, Faculty of FSKIK, Universiti Pendidikan Sultan Idris. Perak, \\ Malaysia.
}

\section{Article History}

Received:

15.01.2021

Revised:

23.04.2021

Accepted:

07.06.2021

*Corresponding Author:

Ali Alrfooh

Email:

amgma78@gmail.com

This is an open access article, licensed under: $\mathrm{CC}-\mathrm{BY}-\mathrm{SA}$
Abstract: Despite many studies being conducted on mobile learning acceptance, few investigate mobile-based assessment acceptance. The objectives of this study are: to provide valuable insights into current research on mobile-based assessment literature, and to identify the main gaps in the mobile-based assessment acceptance literature. Therefore, the present study systematically reviews 48 previous studies and eight articles related to mobile-based assessment acceptance to provide a comprehensive analysis of the articles published from 2009 to 2019 . Findings indicate that majority of mobile-based assessment studies focused on evaluating the effectiveness and performance of mobile-based assessment system and conducted at the secondary school level. In addition, this study identified several gaps. Further research is needed to study the acceptance problem of a mobile-based assessment system. More investigation is required to predict which external factors that can enhance the acceptance and use of mobile-based assessment among students. The findings of this review study provide a valuable reference for researchers about the current trend of mobile-based assessment research as well as the research gaps that should be covered in future studies.

Keywords: Acceptance Studies, Mobile-Based Assessment, Systematic Review. 


\section{Introduction}

Because of the advances in mobile device features, mobile learning is increasingly being used as a new tool for learning and education. Researchers have provided evidence that mobile learning has many benefits for education such as learning anywhere and anytime, accessibility, and interactivity [1], [2], [3]. These benefits have motivated many universities to adopt mobile devices as an informal assessment tool known as "Mobile-Based Assessment (MBA)". According to Johnson et al [4], the MBA has become another delivery tool for assessments that are used to complement paper and computer-based testing. Nikou and Economides [5] defined MBA as a new mode of assessment based on the use of mobile and wireless technologies. MBA provides useful functionality and the opportunity to assess learning differently than through paper or computer-based assessments [5]. MBA is flexible because it allows for assessment both inside and outside the classroom [6], and provides immediate and personalised feedback [7].

However, despite the important and exciting benefits that provide by MBA, the use and acceptance of MBA is a contested issue in the literature that still needs further investigation [5] [8]. Many researchers focused on their studies on studying the acceptance of mobile learning in higher education [9] [10], the use of mobile information system services in universities environment [11] and adoption of mobile technologies [12] [13]. Few studies have investigated the use and acceptance of MobileBased Assessment. The ones that did examine the acceptance of MBA ignored some critical issues that may enhance the acceptance of MBA such as enjoyment, learning content and usability. Moreover, none of the studies provides a comprehensive review of the current status of research related to MBA.

This study is essential for two reasons, i.e. the first is that previous research indicated the determinants of MBA acceptance are still not clear. Identifying these determinants is one of the most critical issues in the success of any new system [14]. Second, there is a gap in the literature regarding the acceptance of MBA.

The current study addresses this gap by providing a systematic review and synthesis of the studies related to MBA acceptance. Understanding the factors that influence the acceptance of MBA in the collected studies will assist the MBA scholars to plan forward to investigate the impact of other factors that are missing in existing literature.

The objective of this study is achieved by addressing the following research questions:

RQ1 : In the selected studies on MBA, What are the main research purposes?

RQ2 : Regarding the second research question, a systematic review of the studies related to acceptance, adoption or intention to use of MBA was carried out. Specifically, this review addressed the following research questions:

RQ2a : In the selected studies of MBA acceptance, what are the main factors that have been studied?

RQ2b : In the selected studies of MBA acceptance, what are the main models and theories of technology acceptance that were used?

RQ2c : In the selected studies of MBA acceptance, what are the main research design and method?

RQ2d : In the selected studies of MBA acceptance, what are the primary disciplines/contexts and assessment types?

RQ2e : In the selected studies of MBA acceptance, what are the primary educational levels and learning domain?

RQ2f : In the selected studies of MBA acceptance, what are the years of publication?

RQ2g : In the selected studies of MBA acceptance, what are the active countries in the context?

\section{Literature Review}

There are several previous reviews conducted on mobile learning that focused on the acceptance of mobile learning among students as a prior step to the success of mobile learning applications [15], [16]. Also, there are many studies focused on mobile learning in higher education [17] [18], the use of mobile learning in specific learning domains such as science and engineering [16]. Most of these studies confirm that mobile learning is a useful and promising tool for supporting students' learning and improving their learning achievements and performance.

Although several studies, investigated mobile-based assessment acceptance in a mobile learning context, mobile-based assessment acceptance among students should also be studied in its context [5] 
[7]. The previous reviews provided an important research synthesis on mobile learning acceptance literature. None of the previous studies offers a comprehensive review of the current status of research on mobile-based assessment acceptance. This study is the first study to provide a detailed analysis of the literature review about mobile-based assessment acceptance.

\section{Methodology}

In this study, distinct steps were taken to conduct a rigorous systematic review of the literature related to mobile-based assessment acceptance. The review process was performed based on existing guidelines established by Kitchenham \& Charters [19] which includes:

(1) identifying the inclusion and exclusion criteria

(2) determining the data sources and search strategies, and

(3) data analysis and coding.

This review is considered an essential step before conducting any research paper, and it helps to build the foundation for knowledge accumulation. It also helps to identify the areas that previous studies have missed [20]. The following subsections describe in detail the steps used for conducting the systematic review in this study.

\subsection{Identifying the Inclusion and Exclusion Criteria}

In the first step of review, a collection of inclusion and exclusion criteria were determined that were used during the selection of articles.

Table 1 shows the inclusion and exclusion criteria for mobile-based assessment acceptance.

Table 1. Inclusion and Exclusion Criteria in the Research Process

\begin{tabular}{|c|c|}
\hline Inclusion criteria & Exclusion criteria \\
\hline $\begin{array}{l}\text { 1. The selected studies that include mobile } \\
\text { based assessment acceptance }\end{array}$ & $\begin{array}{l}\text { 1. Exclude each study which does not use } \\
\text { technology acceptance models in } \\
\text { mobile-based assessment }\end{array}$ \\
\hline $\begin{array}{l}\text { 2. The selected studies that include } \\
\text { technology acceptance models }\end{array}$ & $\begin{array}{l}\text { 2. Exclude studies in mobile-based } \\
\text { assessment development }\end{array}$ \\
\hline $\begin{array}{l}\text { 3. The selected studies that involve learning } \\
\text { and teaching }\end{array}$ & $\begin{array}{l}\text { 3. Exclude each study, not in the context } \\
\text { of learning and teaching }\end{array}$ \\
\hline $\begin{array}{l}\text { 4. Must have been published between } 2009 \\
\text { to } 2019\end{array}$ & \\
\hline 5. Must be written in English & \\
\hline
\end{tabular}

\subsection{Determining the Data Sources and Search Strategies}

In the second step of systematic literature review, we collected a large number of studies through a search in the following popular databases: Google Scholar, Wiley, IEEE, ScienceDirect and Springer. The main keywords that were used in the search process are: "Technology Acceptance Models" AND "Mobile Based Assessment Acceptance". We found through the search process 1033 articles using the keywords above and classified based on the identified databases as shown in Table 1.

Then, we excluded all the items that we found as duplicated, which was 200 articles; thus, the total number of the collected items was reduced to 833. After that, the remaining articles were filtered based on the criteria in Table 1. Finally, 54 items met the inclusion criteria and are used in the analysis process.

Figure 1 illustrates the systematic review process for this study. 


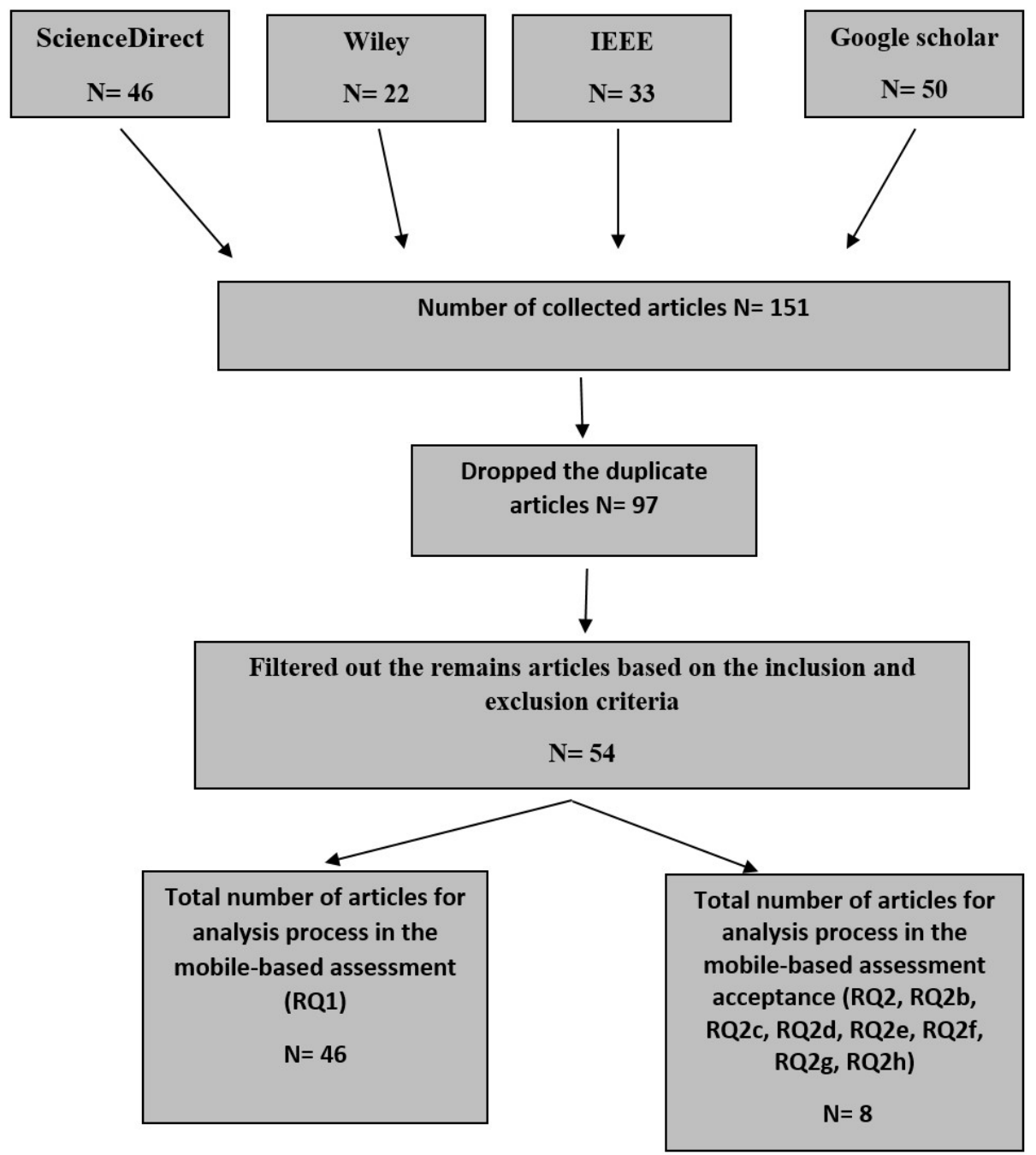

Figure1. Research Process for the Collected Articles

\section{Finding and Discussion}

In this research, the following characteristics were investigated and coded including (RQ1) research purpose (with the focus on the mobile-based assessment), (RQ2) with an emphasis on the mobilebased assessment acceptance, adoption or intention to use interns (RQ2a) external factors, (RQ2b) the impact of external factors, (RQ2c) Technology acceptance models used, (RQ2d) research method (questionnaires, interviews or mixed), (RQ2e) research contexts (e.g., IT and computer science, education, engineering, etc.), (RQ2f) educational levels (e.g., higher education, secondary school, etc.), (RQ2g) publications of year, (RQ2h) country. In the analysis process, the authors focused on the articles that studied the acceptance process of mobile-based assessment based on the technology acceptance models like the TAM and UTAUT.

\section{Conclusion}

This review study only focused on articles published in four top-ranked databases like ScienceDirect, Wiley, IEEE and Google scholar. Based on that, these databases may not provide all articles published on mobile-based assessment acceptance. Future research could expand the current study by including articles from other databases such as Emerald, Springer, Sage, ACM Digital Library and others. 


\section{References}

[1] A. Man and M. Man, "Empirical Investigation to Explore Factors That Achieve High Quality of Mobile Learning System Based on Students' Perspectives," Engineering science and technology, an international journal, vol. 19, no. 3, pp. 1314-1320, 2016.

[2] A. Althunibat, "Determining the Factors Influencing Students' Intention to Use m-learning in Jordan Higher Education," Computers in Human Behavior, vol. 52, pp. 65-71, 2015.

[3] Y. T. Sung, K. E. Chang, and T. C. Liu, "The Effects of Integrating Mobile Devices with Teaching and Learning on Students' Learning Performance: A Meta-Analysis and Research Synthesis," Computers \& Education, vol. 94, pp. 252-27, 2016.

[4] L. Johnson, S. A.Becker, M. Cummins, V. Estrada, A. Freeman, and C. Hall, (2016). "NMC horizon report: 2016 higher education edition (pp. 1-50). The New Media Consortium.

[5] S. A. Nikou, and A. A.Economides, "Mobile-Based Assessment: Integrating Acceptance and Motivational Factors into A Combined Model of Self-Determination Theory and Technology Acceptance," Computers in Human Behavior, vol. 68, pp. 83-95, 2017.

[6] Y. Miyasawa, and M. Ueno, "Mobile Testing for Authentic Assessment in the Field. in International Conference on Artificial Intelligence in Education," Springer, Berlin, Heidelberg, pp. 619-623, July 2013.

[7] S. A. Nikou, and A. A. Economides, "Factors That Influence Behavioral Intention to Use Mobile-Based Assessment: A STEM Teachers' Perspective," British Journal of Educational Technology, 2018.

[8] L. Briz-Ponce, and J. A. Juanes-Méndez, "Mobile Devices and Apps, Characteristics and Current Potential on Learning," Journal of Information Technology Research (JITR), vol. 8, no. 4, pp. 26-37, 2015.

[9] M. A. Almaiah, M. A. Jalil, and M. Man, "Extending the TAM to Examine the Effects of Quality Features on Mobile Learning Acceptance," Journal of Computers in Education, vol. 3, no. 4, pp. 453-485, 2016.

[10] M. Al-Emran, H. M. Elsherif, and K. Shaalan, "Investigating Attitudes Towards the use of Mobile Learning in Higher Education," Computers in Human Behavior, vol. 56, pp. 93-102, 2016.

[11] M. A. Almaiah, and A. Al Mulhem, "Analysis of The Essential Factors Affecting of Intention to use of Mobile Learning Applications: A Comparison between Universities Adopters and NonAdopters," Education and Information Technologies, pp. 1-36, 2018.

[12] A. Abu-Al-Aish, and S. Love, "Factors Influencing Students' Acceptance of M-Learning: An Investigation in Higher Education," The International Review of Research in Open and Distributed Learning, vol. 14, no. 5, 2013.

[13] S. Y. Park, M. W. Nam, and S. B. Cha, "University Students' Behavioral Intention to Use Mobile Learning: Evaluating the Technology Acceptance Model," British Journal of Educational Technology, vol. 43, no. 4, pp. 592-605, 2012.

[14] S. A. Nikou, and A. A. Economides, "Mobile-Based Assessment: A Literature Review of Publications in Major Referred Journals from 2009 to 2018," Computers \& Education, vol. 125, pp. 101-119, 2018.

[15] H. Crompton, D. Burke, and K. H. Gregory, "The use of mobile learning in PK-12 education: A systematic review," Computers \& Education, vol. 110, pp. 51-63, 2017.

[16] J. M. Zydney, and Z. Warner, "Mobile Apps for Science Learning: Review of research," Computers \& Education, vol. 94, pp. 1-17, 2016.

[17] M. Alrasheedi, L. F. Capretz, and A. Raza, "A Systematic Review of the Critical Factors for Success of Mobile Learning in Higher Education University Students' Perspective," Journal of Educational Computing Research, vol. 52, no. 2, pp. 257-276, 2015.

[18] C. Pimmer, M. Mateescu, and U. Gröhbiel, "Mobile and Ubiquitous Learning in Higher Education Settings. A Systematic Review of Empirical Studies," Computers in Human Behavior, vol. 63, pp. 490-501, 2016.

[19] B. Kitchenham, and S. Charters, Guidelines for Performing Systematic Literature Reviews in Software Engineering, 2007.

[20] N. Marangunić, and A. Granić, "Technology Acceptance Model: A Literature Review from 1986 to 2013," Universal Access in the Information Society, vol. 14, no. 1, pp. 81-95, 2015. 